\title{
Nitrofurantoin and fosfomycin for resistant urinary tract infections: old drugs for emerging problems
}

\section{Bradley J Gardiner \\ Infectious diseases physician?}

\section{Andrew J Stewardson} Infectious diseases physician?

lain J Abbott

Infectious diseases physician and Clinical microbiologist $t^{1,2}$

\section{Anton Y Peleg}

Director and Research group leader ${ }^{3}$

1 Department of Infectious Disease, Alfred Health and Central Clinical

School, Monash University, Melbourne

${ }^{2}$ Department of Medical Microbiology and Infectious Diseases, Research and

Development Unit, Erasmus Medical Centre, Rotterdam, The Netherlands

${ }^{3}$ Biomedicine Discovery Institute, Department of Microbiology, Monash University, Melbourne

\section{Keywords}

antibiotic resistance, fosfomycin, nitrofurantoin urinary tract infection

Aust Prescr 2019;42:14-9 https://doi.org/10.18773/ austprescr.2019.002

\section{SUMMARY}

Uncomplicated urinary tract infection is one of the most common indications for antibiotic use in the community. However, the Gram-negative organisms that can cause the infection are becoming more resistant to antibiotics.

Many multidrug resistant organisms retain susceptibility to two old antibiotics, nitrofurantoin and fosfomycin. Advantages over newer drugs include their high urinary concentrations and minimal toxicity.

Fosfomycin is a potential treatment option for patients with uncomplicated urinary tract infection due to resistant organisms. Nitrofurantoin may be more effective and can be used for urinary infections in pregnant women.

\section{Introduction}

Antimicrobial resistance is increasing worldwide, resulting in infections that are more difficult to treat and associated with higher mortality, morbidity and cost. ${ }^{1-3}$ In Australia, multidrug resistant Gram-negative bacilli are responsible for a rising proportion of community-acquired uncomplicated urinary tract infections. Consequently, empiric therapy is more likely to fail. This has resulted in increasing numbers of patients with uncomplicated urinary tract infections requiring hospitalisation for intravenous antibiotics because there are no oral treatment options.

Limited Australian data are available for antimicrobial resistance rates in community-onset urinary tract infections. ${ }^{4,5}$ One large national survey of urinary isolates from 2015 found resistance rates in Escherichia coli of 43\% for ampicillin, 9\% for amoxicillin with clavulanic acid, $16 \%$ for cefazolin, $22 \%$ for trimethoprim, and $7 \%$ for ciprofloxacin. ${ }^{6}$ It is likely that resistance rates have continued to rise since then.

There are few new antibiotics on the horizon and those that have been recently approved are mostly for intravenous use, so older 'forgotten' drugs are being re-explored for the treatment of cystitis. ${ }^{7-10}$ Nitrofurantoin and fosfomycin are old antibiotics. They share some important properties including high concentrations in the urinary tract, a minimal impact on gastrointestinal flora and a low propensity for resistance (Table).

\section{Nitrofurantoin}

Nitrofurantoin has been available since 1953, and in Australia since the 1970s. Its exact mechanism of action is not well understood and presumably multifactorial. Nitrofurantoin requires reduction by bacterial enzymes producing 'highly reactive electrophilic' metabolites. These then inhibit protein synthesis by interfering with bacterial ribosomal proteins."

Nitrofurantoin has $80 \%$ oral bioavailability, and approximately $25 \%$ is excreted unchanged in the urine, with only a small portion reaching the colon. ${ }^{12}$ Like fosfomycin, therapeutic concentrations are only reached in the urinary tract, ${ }^{13}$ so the clinical use of nitrofurantoin is limited to the treatment of uncomplicated urinary tract infection in women. Administration with food results in higher urinary concentrations and fewer gastrointestinal adverse effects.

\section{Antimicrobial activity}

Nitrofurantoin is active against common causes of urinary tract infection including E. coli, Citrobacter and Enterococcus. Klebsiella and Enterobacter are less reliably susceptible. Serratia, Acinetobacter, Morganella, Proteus and Pseudomonas are usually resistant. ${ }^{14}$ Overall, resistance to nitrofurantoin is uncommon and many multidrug resistant organisms retain susceptibility. ${ }^{15-17}$ Australian data are limited, but studies suggest resistance rates in E. coli of $1-2 \% .4,6$ 


\section{Table Features of nitrofurantoin and fosfomycin}

\begin{tabular}{|c|c|c|}
\hline Characteristic & Nitrofurantoin & Fosfomycin \\
\hline Year of discovery & 1953 & 1969 \\
\hline \multirow[t]{4}{*}{ Formulations } & Nitrofurantoin macrocrystal & Fosfomycin trometamol \\
\hline & 50 mg, 100 mg capsules & $3 \mathrm{~g}$ sachet containing granules to be dissolved in \\
\hline & Slow-release formulation not available in Australia & water \\
\hline & Older microcrystal formulation less available now (more adverse effects) & $\begin{array}{l}\text { Intravenous formulation available but for } \\
\text { specialised use only }\end{array}$ \\
\hline \multirow[t]{2}{*}{ Pharmacokinetics } & High urinary concentrations & Long half-life with high urinary concentrations \\
\hline & Serum concentrations negligible & $\begin{array}{l}\text { Serum concentrations inadequate for treatment of } \\
\text { systemic infection }\end{array}$ \\
\hline Mechanism of action & $\begin{array}{l}\text { Not well understood, multifactorial, inhibits ribosomal protein } \\
\text { synthesis }\end{array}$ & $\begin{array}{l}\text { Inhibits pyruvyl transferase and therefore cell wall } \\
\text { synthesis }\end{array}$ \\
\hline \multirow[t]{3}{*}{ Spectrum of activity } & Mostly susceptible: E. coli, Enterococcus & Mostly susceptible: E. coli \\
\hline & $\begin{array}{l}\text { Variably susceptible: Klebsiella, Enterobacter, Citrobacter } \\
\text { and Providencia }\end{array}$ & $\begin{array}{l}\text { Variably susceptible: Klebsiella, Proteus, Citrobacter, } \\
\text { Enterobacter, Pseudomonas and Enterococcus }\end{array}$ \\
\hline & $\begin{array}{l}\text { Typically resistant: Proteus, Serratia, Acinetobacter, Morganella } \\
\text { and Pseudomonas }\end{array}$ & Typically resistant: Morganella and Acinetobacter \\
\hline Resistance & Uncommon & Uncommon \\
\hline Indications & Uncomplicated urinary tract infection in women & Uncomplicated urinary tract infection in women \\
\hline Dosing & 50-100 mg 4 times a day for 5 days & Single $3 \mathrm{~g}$ oral dose \\
\hline \multirow[t]{2}{*}{ Adverse events } & Infrequent, mainly gastrointestinal & \multirow{2}{*}{$\begin{array}{l}\text { Infrequent, mainly gastrointestinal ( } 9 \% \text { diarrhoea, } \\
4 \% \text { nausea) }\end{array}$} \\
\hline & Rare reports of pulmonary or liver toxicity, peripheral neuropathy & \\
\hline $\begin{array}{l}\text { Pregnancy and } \\
\text { breastfeeding }\end{array}$ & $\begin{array}{l}\text { Category } A \text {, although not recommended beyond } 38 \text { weeks gestation } \\
\text { due to risk of haemolytic anaemia in neonates. For this reason it is } \\
\text { also best to avoid during the first month of breastfeeding }\end{array}$ & $\begin{array}{l}\text { Category B2, small amounts excreted in breast milk } \\
\text { so not recommended in breastfeeding }\end{array}$ \\
\hline Children & Avoid $<1$ month of age & Avoid $<12$ years of age \\
\hline Interactions & Few significant drug interactions & $\begin{array}{l}\text { Co-administration with metoclopramide can lower } \\
\text { serum and urine concentrations }\end{array}$ \\
\hline \multirow[t]{2}{*}{ Renal impairment } & Contraindicated if $\mathrm{CrCl}<30 \mathrm{~mL} / \mathrm{min}$ & Dose reduction required if $\mathrm{CrCl}<50 \mathrm{~mL} / \mathrm{min}$ \\
\hline & Cautious use between $\mathrm{CrCl} 30-60 \mathrm{~mL} / \mathrm{min}$ if benefits outweigh risks & \\
\hline
\end{tabular}

$\mathrm{CrCl}$ creatinine clearance

\section{Efficacy and safety}

A meta-analysis of 27 older controlled trials (4807 patients) found clinical cure rates of $79-92 \%$, similar to comparator antibiotics. Only mild toxicities (most commonly gastrointestinal) and no cases of pulmonary fibrosis or hepatotoxicity were reported..$^{18}$ Dosing recommendations for the standard formulation are 50-100 mg four times daily. There is a long-acting formulation available overseas, but not in Australia, which can be dosed twice daily. This slow-release formulation (100 mg three times daily) was used in a recent open-label comparison with fosfomycin. The cure rate was $70 \%$ in the nitrofurantoin group..$^{19}$
Historically nitrofurantoin was thought to be contraindicated if the creatinine clearance was less than $60 \mathrm{~mL} /$ minute due to an increased risk of toxicity. However, recommendations have been changing to allow cautious, short-term use in patients with mild renal impairment $(30-60 \mathrm{~mL} / \mathrm{min}$ ) if there are no alternative antibiotics. ${ }^{20,21}$ Nitrofurantoin can be used to treat cystitis in pregnancy (although not beyond 38 weeks gestation due to the risk of haemolytic anaemia in the neonate).

Nitrofurantoin became a preferred drug in the international consensus guidelines for urinary tract infection in 2010.22 These emphasised the lower rates of 'collateral damage' on gastrointestinal flora. ${ }^{23-24}$ 
It remains to be seen if resistance rates increase as a consequence of this recommendation and the subsequent rise in nitrofurantoin prescribing. The true incidence of major hepatic and pulmonary toxicity is unclear, but this appears to be more common with long-term use in the elderly. ${ }^{14}$ For the short-term treatment of uncomplicated urinary tract infection in otherwise healthy young women, nitrofurantoin is a safe and effective choice, and overall efficacy and rates of adverse events appear similar to comparator antibiotics. In patients with infections due to multidrug resistant organisms and therefore few alternative treatment options, we recommend using $100 \mathrm{mg}$ four times daily for five days, administered with food to optimise absorption and efficacy.

\section{Fosfomycin}

Fosfomycin was first isolated in Spain in 1969, and was introduced in Europe throughout the 1970s. ${ }^{25}$ It is a small molecule from a unique drug class that acts by inhibiting pyruvyl transferase. This enzyme is responsible for synthesising the precursors of peptidoglycan, the key component of the bacterial cell wall. Uptake in the USA was initially limited due to problems with susceptibility testing, but this was standardised in 1983.

Fosfomycin trometamol, an oral formulation that can be taken as a single $3 \mathrm{~g}$ dose, was introduced in 1995. In many countries it is now a first-line treatment option for uncomplicated urinary tract infection in women. ${ }^{22}$ This single-dose regimen is attractive due to better adherence and is generally well tolerated. While transient gastrointestinal disturbance can occur, serious adverse events are rare. ${ }^{26}$

In Australia, fosfomycin was only previously available via the Special Access Scheme. The Therapeutic Goods Administration has now approved it for acute uncomplicated lower urinary tract infection, in females more than 12 years of age, caused by susceptible organisms (Enterobacteriaceae including E. coli, and Enterococcus faecalis).

\section{Antimicrobial activity}

Susceptibility testing for fosfomycin is available, but can be complicated and is not necessarily routine in Australian microbiology laboratories. Fosfomycin is most active against $E$. coli, and minimum inhibitory concentrations are typically low. ${ }^{27-29}$ Other urinary pathogens such as Klebsiella, Proteus, Citrobacter, Enterobacter, Pseudomonas and Enterococcus have variable susceptibility. ${ }^{30-32}$ Morganella morganii and Acinetobacter are typically resistant. ${ }^{28}$ Urinary concentrations following a single $3 \mathrm{~g}$ dose are generally sufficient to treat patients infected with susceptible organisms, although some recent data suggest more variability in urinary concentrations than previously thought. ${ }^{33,34}$

As fosfomycin has a unique structure there is minimal cross-resistance with other antibiotics. At present, many multidrug resistant isolates remain susceptible to fosfomycin, even in geographic regions where there has been widespread use of the drug. ${ }^{35,36}$ No comprehensive studies examining fosfomycin susceptibility have been conducted in Australia.

While resistant subpopulations of bacteria may develop with fosfomycin exposure, resistant strains do not seem to easily survive in vivo. ${ }^{32,37-40}$ However, there are multiple resistance mechanisms and there are reports of increasing resistance correlating with higher fosfomycin usage in Spain. ${ }^{32,41-43}$ Plasmidmediated resistance, which could disseminate more readily, has been described in Japan, ${ }^{44}$ and among livestock ${ }^{45}$ and pets ${ }^{46}$ in China.

\section{Efficacy and safety}

Historically, the clinical efficacy of fosfomycin was thought to be similar to antibiotics such as trimethoprim, trimethoprim/sulfamethoxazole, fluoroquinolones, beta-lactams and nitrofurantoin, with reported cure rates of 75-90\%. ${ }^{47-51}$ However, methodological flaws in the older studies may have resulted in clinical efficacy being overestimated. A recent large randomised trial found a lower clinical cure rate with fosfomycin compared with nitrofurantoin (58\% vs 70\%, $p=0.004$ ). ${ }^{19}$ While some recent observational studies have demonstrated fosfomycin efficacy in uncomplicated urinary tract infection caused by resistant organisms, ${ }^{52-56}$ including non-inferiority to carbapenems, ${ }^{57,58}$ there are reports of treatment failures particularly with Klebsiella. ${ }^{59}$

As low serum concentrations lead to treatment failures, fosfomycin is not appropriate for patients with bacteraemia or upper urinary tract infections such as pyelonephritis. Occasionally, longer courses have been used to treat complicated urinary tract infection, for example as completion therapy when there are no oral alternatives to intravenous antibiotics. ${ }^{57}$ There is also an emerging role in prostatitis and perioperative prophylaxis for urological procedures in men. ${ }^{60-62}$ Specialist infectious diseases input should be sought for these complex cases if off-label use or prolonged courses of therapy are being considered.

Fosfomycin is generally well tolerated, with adverse events rare and usually transient. Gastrointestinal events (9\% diarrhoea, $4 \%$ nausea) have been most commonly reported with rare reports of other more serious problems. ${ }^{26} \mathrm{Co}$-administration with metoclopramide can lower serum and urinary concentrations and should be avoided, but there are few other problematic drug 
interactions. Fosfomycin is classified in pregnancy category B2. It is not recommended in breastfeeding as small amounts are excreted in breast milk. Given there are minimal data on use in children under 12 years of age, it is not advised for this group.

In Australia, we currently recommend reserving fosfomycin for the treatment of uncomplicated urinary tract infection in patients when the standard first-line drugs are not an option. Part of the rationale behind this is to minimise the emergence of resistance and prolong the usefulness of fosfomycin for patients without alternative options. ${ }^{35}$ As resistance to other drugs inevitably rises and local experience increases, fosfomycin may become a first-line option in the future.

\section{Antibiotic resistance}

While re-exploring older 'forgotten' drugs like nitrofurantoin and fosfomycin is a useful strategy, it represents only part of the multifaceted response required to tackle the complex problem of antimicrobial resistance and 'preserve the miracle' of antimicrobials over the coming decades. ${ }^{63}$ As we have seen historically with virtually all other antibiotics, resistance is likely to emerge as usage increases. It remains to be seen how long this will take, to what extent it will occur and whether it will be via dissemination of existing resistance mechanisms or evolution of new ones. The increasing failure of standard empirical therapy for urinary tract infection is foreseeable, and it is likely that more patients will require microbiological testing before starting antibiotics, not only for individualised patient management but also for broader epidemiological surveillance to inform guideline recommendations.
Consultation with an infectious diseases specialist can assist with the management of patients with multidrug resistant infections and leads to better outcomes. ${ }^{64}$ Other important strategies include the development of new antimicrobial drugs, preserving those currently available by judicious use, implementation of comprehensive antimicrobial stewardship programs and stringent infection control practices worldwide to reduce the spread of resistant organisms.

\section{Conclusion}

Nitrofurantoin is suitable for uncomplicated lower urinary tract infections. Bacterial resistance is uncommon.

Fosfomycin is a safe and effective antibacterial drug for urinary tract infections, but its use should be limited to delay the development of resistance. It will prove to be a useful treatment option for community-based treatment of patients with resistant organisms. $\varangle$

Bradley Gardiner and lain Abbott are supported by Australian Government National Health and Medical Research Council (NHMRC) Research Training Program Scholarships (APP1150351 and APP1114690). Andrew Stewardson is supported by an NHMRC Fellowship (APP1141398). Anton Peleg is part funded through an NHMRC Practitioner Fellowship (APP1117940) and is the recipient of an investigator-initiated research grant from Merck, Sharp \& Dohme.

\section{REFERENCES}

1. Walker E, Lyman A, Gupta K, Mahoney MV, Snyder GM, Hirsch EB. Clinical management of an increasing threat: outpatient urinary tract infections due to multidrug-resistant uropathogens. Clin Infect Dis 2016;63:960-5. https://doi.org/ 10.1093/cid/ciw396

2. Prakash V, Lewis JS 2nd, Herrera ML, Wickes BL, Jorgensen JH. Oral and parenteral therapeutic options for outpatient urinary infections caused by Enterobacteriaceae producing CTX-M extended-spectrum $\beta$-lactamases. Antimicrob Agents Chemother 2009;53:1278-80. https://doi.org/10.1128/AAC.01519-08

3. Spellberg B, Guidos R, Gilbert D, Bradley J, Boucher HW, Scheld WM, et al.; Infectious Diseases Society of America. The epidemic of antibiotic-resistant infections: a call to action for the medical community from the Infectious Diseases Society of America. Clin Infect Dis 2008;46:155-64. https://doi.org/10.1086/524891

4. Turnidge JD, Gottlieb T, Mitchell DH, Coombs GW, Pearson JC, Bell JM; Australian Group on Antimicrobial Resistance. Australian Group on Antimicrobial Resistance Community-onset Gram-negative Surveillance Program annual report, 2010. Commun Dis Intell Q Rep 2013;37:E219-23.

5. Turnidge JD, Gottlieb T, Mitchell DH, Coombs GW, Daly DA, Bell JM; Australian Group on Antimicrobial Resistance. Enterobacteriaceae Sepsis Outcome Programme annual report, 2013. Commun Dis Intell Q Rep 2014;38:E327-33.
6. Australian Commission on Safety and Quality in Health Care. AURA 2017: second Australian report on antimicrobial use and resistance in human health. Sydney: ACSQHC; 2017. https://www.safetyandquality.gov.au/publications/secondaustralian-report-on-antimicrobial-use-and-resistance-inhuman-health [cited 2019 Jan 3]

7. Pulcini C, Mohrs S, Beovic B, Gyssens I, Theuretzbacher U, Cars O; ESCMID Study Group for Antibiotic Policies (ESGAP), ReAct Working Group on Old Antibiotics. Forgotten antibiotics: a follow-up inventory study in Europe, the USA, Canada and Australia. Int J Antimicrob Agents 2017;49:98-101. https://doi.org/10.1016/j.ijantimicag.2016.09.029

8. Boucher HW, Talbot GH, Benjamin DK Jr, Bradley J, Guidos RJ, Jones RN, et al.; Infectious Diseases Society of America. 10 x '20 Progress--development of new drugs active against gram-negative bacilli: an update from the Infectious Diseases Society of America. Clin Infect Dis 2013;56:1685-94. https://doi.org/10.1093/cid/cit152

9. Gardiner BJ, Golan Y. Ceftazidime-avibactam (CTZ-AVI) as a treatment for hospitalized adult patients with complicated intra-abdominal infections. Expert Rev Anti Infect Ther 2016;14:451-63. https://doi.org/10.1586/14787210.2016.1173542

10. Maseda E, Aguilar L, Gimenez MJ, Gilsanz F. Ceftolozane/ tazobactam (CXA 201) for the treatment of intra-abdominal infections. Expert Rev Anti Infect Ther 2014;12:1311-24. https://doi.org/10.1586/14787210.2014.950230 
11. McOsker CC, Fitzpatrick PM. Nitrofurantoin: mechanism of action and implications for resistance development in common uropathogens. J Antimicrob Chemother 1994;33 Suppl A:23-30. https://doi.org/10.1093/jac/33.suppl_A.23

12. Cunha BA. New uses for older antibiotics: nitrofurantoin, amikacin, colistin, polymyxin B, doxycycline, and minocycline revisited. Med Clin North Am 2006;90:1089-107. https://doi.org/10.1016/j.mcna.2006.07.006

13. Cunha BA. Nitrofurantoin--current concepts. Urology 1988;32:67-71. https://doi.org/10.1016/0090-4295(88)90460-8

14. Grayson ML, Cosgrove SE, Crowe SM, Hope W, Mccarthy JS Mills J, et al., editors. Kucers' the use of antibiotics: a clinical review of antibacterial, antifungal, antiparasitic and antiviral drugs. 7th ed. Boca Raton (FL): CRC Press; 2017.

15. Sanchez GV, Babiker A, Master RN, Luu T, Mathur A Bordon J. Antibiotic resistance among urinary isolates from female outpatients in the United States in 2003 and 2012. Antimicrob Agents Chemother 2016;60:2680-3. https://doi.org/10.1128/AAC.02897-15

16. Sanchez GV, Baird AM, Karlowsky JA, Master RN, Bordon JM. Nitrofurantoin retains antimicrobial activity against multidrug-resistant urinary Escherichia coli from US outpatients. J Antimicrob Chemother 2014;69:3259-62. https://doi.org/10.1093/jac/dku282

17. Sandegren L, Lindqvist A, Kahlmeter G, Andersson DI. Nitrofurantoin resistance mechanism and fitness cost in Escherichia coli. J Antimicrob Chemother 2008;62:495-503. https://doi.org/10.1093/jac/dkn222

18. Huttner A, Verhaegh EM, Harbarth S, Muller AE, Theuretzbacher U, Mouton JW. Nitrofurantoin revisited: a systematic review and meta-analysis of controlled trials. J Antimicrob Chemother 2015;70:2456-64. https://doi.org/ 10.1093/jac/dkv147

19. Huttner A, Kowalczyk A, Turjeman A, Babich T, Brossier C, Eliakim-Raz N, et al. Effect of 5-day nitrofurantoin vs singledose fosfomycin on clinical resolution of uncomplicated lower urinary tract infection in women: a randomized clinical trial. JAMA 2018;319:1781-9. https://doi.org/10.1001/ jama.2018.3627

20. American Geriatrics Society 2015 Beers Criteria Update Expert Panel. American Geriatrics Society 2015 updated Beers criteria for potentially inappropriate medication use in older adults. J Am Geriatr Soc 2015;63:2227-46. https://doi.org/10.1111/jgs.13702

21. Singh N, Gandhi S, McArthur E, Moist L, Jain AK, Liu AR, et al. Kidney function and the use of nitrofurantoin to treat urinary tract infections in older women. CMAJ 2015;187:648-56. https://doi.org/10.1503/cmaj.150067

22. Gupta K, Hooton TM, Naber KG, Wullt B, Colgan R, Miller LG, et al.; Infectious Diseases Society of America; European Society for Microbiology and Infectious Diseases. International clinical practice guidelines for the treatment of acute uncomplicated cystitis and pyelonephritis in women: a 2010 update by the Infectious Diseases Society of America and the European Society for Microbiology and Infectious Diseases. Clin Infect Dis 2011;52:e103-20. https://doi.org/ 10.1093/cid/ciq257

23. Stewardson AJ, Vervoort J, Adriaenssens N, Coenen S, Godycki-Cwirko M, Kowalczyk A, et al.; SATURN WP1 Study Group; SATURN WP3 Study Group. Effect of outpatient antibiotics for urinary tract infections on antimicrobial resistance among commensal Enterobacteriaceae: a multinational prospective cohort study. Clin Microbiol Infect 2018;24:972-9. https://doi.org/10.1016/j.cmi.2017.12.026

24. Stewardson AJ, Gaia N, Francois P, Malhotra-Kumar S Delémont C, Martinez de Tejada B, et al. Collateral damage from oral ciprofloxacin versus nitrofurantoin in outpatients with urinary tract infections: a culture-free analysis of gut microbiota. Clin Microbiol Infect 2015;21:344 el-11. https://doi.org/10.1016/j.cmi.2014.11.016

25. Hendlin D, Stapley EO, Jackson M, Wallick H, Miller AK, Wolf FJ, et al. Phosphonomycin, a new antibiotic produced by strains of streptomyces. Science 1969;166:122-3. https://doi.org/10.1126/science.166.3901.122

26. larikov D, Wassel R, Farley J, Nambiar S. Adverse events associated with fosfomycin use: review of the literature and analyses of the FDA adverse event reporting system database. Infect Dis Ther 2015;4:433-58. https://doi.org/ $10.1007 / \mathrm{s} 40121-015-0092-8$
27. Seitz M, Stief C, Waidelich R. Local epidemiology and resistance profiles in acute uncomplicated cystitis (AUC) in women: a prospective cohort study in an urban urological ambulatory setting. BMC Infect Dis 2017;17:685. https://doi.org/10.1186/s12879-017-2789-7

28. Cho YH, Jung SI, Chung HS, Yu HS, Hwang EC, Kim SO, et al. Antimicrobial susceptibilities of extended-spectrum beta-lactamase-producing Escherichia coli and Klebsiella pneumoniae in health care-associated urinary tract infection: focus on susceptibility to fosfomycin. Int Urol Nephrol 2015;47:1059-66. https://doi.org/10.1007/s11255-015-1018-9

29. Rossignol L, Vaux S, Maugat S, Blake A, Barlier R, Heym B, et al. Incidence of urinary tract infections and antibiotic resistance in the outpatient setting: a cross-sectional study. Infection 2017;45:33-40. https://doi.org/10.1007/ s15010-016-0910-2

30. Raz R. Fosfomycin: an old--new antibiotic. Clin Microbiol Infect 2012;18:4-7. https://doi.org/10.1111/j.1469-0691.2011.03636.x

31. Keepers TR, Gomez M, Celeri C, Krause KM, Biek D, Critchley I. Fosfomycin and comparator activity agains select Enterobacteriaceae, Pseudomonas, and Enterococcus urinary tract infection isolates from the United States in 2012. Infect Dis Ther 2017;6:233-43. https://doi.org/10.1007/ s40121-017-0150-5

32. Sherry N, Howden B. Emerging Gram negative resistance to last-line antimicrobial agents fosfomycin, colistin and ceftazidime-avibactam - epidemiology, laboratory detection and treatment implications. Expert Rev Anti Infect Ther 2018;16:289-306. https://doi.org/10.1080/14787210.2018.1453807

33. Wijma RA, Koch BC, van Gelder T, Mouton JW. High interindividual variability in urinary fosfomycin concentrations in healthy female volunteers. Clin Microbiol Infect 2018;24:528-32. https://doi.org/ 10.1016/j.cmi.2017.08.023

34. Abbott IJ, Meletiadis J, Belghanch I, Wijma RA, Kanioura L, Roberts JA, et al. Fosfomycin efficacy and emergence of resistance among Enterobacteriaceae in an in vitro dynamic bladder infection model. J Antimicrob Chemother 2018;73:709-19. https://doi.org/10.1093/jac/dkx441

35. Vasoo S, Cunningham SA, Cole NC, Kohner PC, Menon SR, Krause KM, et al. In vitro activities of ceftazidimeavibactam, aztreonam-avibactam, and a panel of older and contemporary antimicrobial agents against carbapenemase-producing Gram-negative bacilli. Antimicrob Agents Chemother 2015;59:7842-6. https://doi.org/10.1128/AAC.02019-15

36. Falagas ME, Maraki S, Karageorgopoulos DE, Kastoris AC, Mavromanolakis E, Samonis G. Antimicrobial susceptibility of multidrug-resistant (MDR) and extensively drugresistant (XDR) Enterobacteriaceae isolates to fosfomycin Int J Antimicrob Agents 2010;35:240-3. https://doi.org/ 10.1016/j.ijantimicag.2009.10.019

37. Martín-Gutiérrez G, Docobo-Pérez F, Rodriguez-Beltrán J, Rodríguez-Martínez JM, Aznar J, Pascual A, et al. Urinary tract conditions affect fosfomycin activity against Escherichia coli strains harboring chromosomal mutations involved in fosfomycin uptake. Antimicrob Agents Chemother 2017;62:e01899-17. https://doi.org/10.1128/ AAC.01899-17

38. Marchese A, Gualco L, Debbia EA, Schito GC, Schito AM. In vitro activity of fosfomycin against gram-negative urinary pathogens and the biological cost of fosfomycin resistance. Int J Antimicrob Agents 2003;22 Suppl 2:53-9. https://doi.org/10.1016/S0924-8579(03)00230-9

39. Nilsson Al, Berg OG, Aspevall O, Kahlmeter G, Andersson DI. Biological costs and mechanisms of fosfomycin resistance in Escherichia coli. Antimicrob Agents Chemother 2003;47:2850-8. https://doi.org/10.1128/AAC.47.9.2850-2858.2003

40. Karageorgopoulos DE, Wang R, Yu XH, Falagas ME. Fosfomycin: evaluation of the published evidence on the emergence of antimicrobial resistance in Gram-negative pathogens. J Antimicrob Chemother 2012;67:255-68. https://doi.org/10.1093/jac/dkr466

41. Oteo J, Bautista V, Lara N, Cuevas O, Arroyo M, Fernández S, et al.; Spanish ESBL-EARS-Net Study Group. Parallel increase in community use of fosfomycin and resistance to fosfomycin in extended-spectrum $\beta$-lactamase (ESBL)producing Escherichia coli. J Antimicrob Chemother 2010;65:2459-63. https://doi.org/10.1093/jac/dkq346 
42. Sorlozano A, Jimenez-Pacheco A, de Dios Luna De Castillo J, Sampedro A, Martinez-Brocal A, Miranda-Casas C, et al. Evolution of the resistance to antibiotics of bacteria involved in urinary tract infections: a 7-year surveillance study. Am J Infect Control 2014:42:1033-8. https://doi.org/ 10.1016/j.ajic.2014.06.013

43. Rodríguez-Avial C, Rodríguez-Avial I, Hernández E, Picazo JJ. [Increasing prevalence of fosfomycin resistance in extended-spectrum-beta-lactamase-producing Escherichia coli urinary isolates (2005-2009-2011)]. Rev Esp Quimioter 2013;26:43-6.

44. Wachino J, Yamane K, Suzuki S, Kimura K, Arakawa Y. Prevalence of fosfomycin resistance among CTX-Mproducing Escherichia coli clinical isolates in Japan and identification of novel plasmid-mediated fosfomycinmodifying enzymes. Antimicrob Agents Chemother 2010;54:3061-4. https://doi.org/10.1128/AAC.01834-09

45. Ho PL, Chan J, Lo WU, Law PY, Li Z, Lai EL, et al. Dissemination of plasmid-mediated fosfomycin resistance fos $A 3$ among multidrug-resistant Escherichia coli from livestock and other animals. J Appl Microbiol 2013;114:695-702. https://doi.org/10.1111/jam.12099

46. Hou J, Huang X, Deng Y, He L, Yang T, Zeng Z, et al. Dissemination of the fosfomycin resistance gene foSA3 with CTX-M $\beta$-lactamase genes and rmtB carried on IncFII plasmids among Escherichia coli isolates from pets in China. Antimicrob Agents Chemother 2012;56:2135-8. https://doi.org/10.1128/AAC.05104-11

47. Stein GE. Comparison of single-dose fosfomycin and a 7-day course of nitrofurantoin in female patients with uncomplicated urinary tract infection. Clin Ther 1999;21:1864-72. https://doi.org/10.1016/S0149-2918(00)86734-X

48. Minassian MA, Lewis DA, Chattopadhyay D, Bovill B, Duckworth GJ, Williams JD. A comparison between singledose fosfomycin trometamol (Monuril) and a 5-day course of trimethoprim in the treatment of uncomplicated lower urinary tract infection in women. Int J Antimicrob Agents 1998;10:39-47. https://doi.org/10.1016/S0924-8579(98)00021-1

49. Fosfomycin for urinary tract infections. Med Lett Drugs Ther 1997;39:66-8

50. Van Pienbroek E, Hermans J, Kaptein AA, Mulder JD. Fosfomycin trometamol in a single dose versus seven days nitrofurantoin in the treatment of acute uncomplicated urinary tract infections in women. Pharm World Sci 1993;15:257-62. https://doi.org/10.1007/BF01871127

51. Falagas ME, Vouloumanou EK, Togias AG, Karadima M, Kapaskelis AM, Rafailidis PI, et al. Fosfomycin versus other antibiotics for the treatment of cystitis: a meta-analysis of randomized controlled trials. J Antimicrob Chemother 2010;65:1862-77. https://doi.org/10.1093/jac/dkq237

52. Neuner EA, Sekeres J, Hall GS, van Duin D. Experience with fosfomycin for treatment of urinary tract infections due to multidrug-resistant organisms. Antimicrob Agents Chemother 2012;56:5744-8. https://doi.org/10.1128/AAC.00402-12

53. Seroy JT, Grim SA, Reid GE, Wellington T, Clark NM. Treatment of MDR urinary tract infections with oral fosfomycin: a retrospective analysis. J Antimicrob Chemother 2016;71:2563-8. https://doi.org/10.1093/jac/dkw178
54. Falagas ME, Kastoris AC, Karageorgopoulos DE, Rafailidis PI. Fosfomycin for the treatment of infections caused by multidrug-resistant non-fermenting Gram-negative bacilli: a systematic review of microbiological, animal and clinical studies. Int J Antimicrob Agents 2009;34:111-20. https://doi.org/10.1016/j.ijantimicag.2009.03.009

55. Rodríguez-Baño J, Alcalá JC, Cisneros JM, Grill F, Oliver A, Horcajada JP, et al. Community infections caused by extended-spectrum beta-lactamase-producing Escherichia coli. Arch Intern Med 2008;168:1897-902. https://doi.org/ 10.1001/archinte.168.17.1897

56. Pullukcu H, Tasbakan M, Sipahi OR, Yamazhan T, Aydemir S, Ulusoy S. Fosfomycin in the treatment of extended spectrum beta-lactamase-producing Escherichia coli-related lower urinary tract infections. Int J Antimicrob Agents 2007;29:62-5. https://doi.org/10.1016/j.ijantimicag.2006.08.039

57. Veve MP, Wagner JL, Kenney RM, Grunwald JL, Davis SL. Comparison of fosfomycin to ertapenem for outpatient or step-down therapy of extended-spectrum $\beta$-lactamase urinary tract infections. Int J Antimicrob Agents 2016;48:56-60. https://doi.org/10.1016/j.ijantimicag.2016.04.014

58. Senol S, Tasbakan M, Pullukcu H, Sipahi OR, Sipahi H, Yamazhan T, et al. Carbapenem versus fosfomycin tromethanol in the treatment of extended-spectrum betalactamase-producing Escherichia coli-related complicated lower urinary tract infection. J Chemother 2010;22:355-7. https://doi.org/10.1179/joc.2010.22.5.355

59. Matthews PC, Barrett LK, Warren S, Stoesser N, Snelling M, Scarborough $\mathrm{M}$, et al. Oral fosfomycin for treatment of urinary tract infection: a retrospective cohort study. BMC Infect Dis 2016;16:556. https://doi.org/10.1186/ s12879-016-1888-1

60. Gardiner BJ, Mahony AA, Ellis AG, Lawrentschuk N, Bolton DM, Zeglinski PT, et al. Is fosfomycin a potential treatment alternative for multidrug-resistant gram-negative prostatitis? Clin Infect Dis 2014;58:e101-5. https://doi.org/ 10.1093/cid/cit704

61. Grayson ML, Macesic N, Trevillyan J, Ellis AG, Zeglinski PT Hewitt $\mathrm{NH}$, et al. Fosfomycin for treatment of prostatitis: new tricks for old dogs. Clin Infect Dis 2015;61:1141-3. https://doi.org/10.1093/cid/civ436

62. Rhodes NJ, Gardiner BJ, Neely MN, Grayson ML, Ellis AG, Lawrentschuk N, et al. Optimal timing of oral fosfomycin administration for pre-prostate biopsy prophylaxis. J Antimicrob Chemother 2015;70:2068-73. https://doi.org/ 10.1093/jac/dkv067

63. Spellberg B, Blaser M, Guidos RJ, Boucher HW, Bradley JS, Eisenstein $\mathrm{BI}$, et al.; Infectious Diseases Society of America (IDSA). Combating antimicrobial resistance: policy recommendations to save lives. Clin Infect Dis 2011;52 Suppl 5:S397-428. https://doi.org/10.1093/cid/cir153

64. Burnham JP, Olsen MA, Stwalley D, Kwon JH, Babcock HM, Kollef MH. Infectious diseases consultation reduces 30-day and 1-year all-cause mortality for multidrug-resistant organism infections. Open Forum Infect Dis 2018;5:ofy026. https://doi.org/10.1093/ofid/ofy026 